\title{
A visibilidade da especialidade e 0 título de especialista
}

$\mathrm{E}$ nfermagem Pediátrica e Enfermagem Neonatológica constituem especialidades da Enfermagem. Além de especialidades, são disciplinas que compõem a formação do enfermeiro generalista, possibilitando ao profissional as competências mínimas essenciais para o cuidado à criança nas diferentes etapas do seu desenvolvimento e condições de saúde. Nesta direção, surge o seguinte questionamento: as vivências da graduação sobre a temática são suficientes para garantir uma assistência qualificada aos neonatos, crianças, adolescentes e suas famílias?

Certamente não. De modo geral, unicamente enfermeiros especialistas em pediatria e neonatologia são potencialmente capazes de qualificar a atenção à saúde, na perspectiva de enfermagem, dos neonatos, crianças, adolescentes e suas famílias nos diferentes cenários de cuidado a medida que conhecem as necessidades próprias de cada faixa etária de acordo com o processo de crescimento e desenvolvimento, conhecem as legislações, políticas e programas de saúde que protegem integralmente as crianças e suas famílias, conhecem as particularidades anatômicas e fisiológicas da criança, utilizam recursos lúdicos como estratégia de comunicação, e sobretudo são capazes de propor e realizar as intervenções de enfermagem apropriadas a cada evento assistencial vivido pela criança e sua família no processo saúde doença

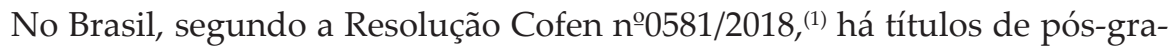
duação obtidos por meio de cursos lato sensu, incluindo-se cursos de especialização ou residência, emitidos por instituições de ensino superior, credenciados no Ministério da Educação-MEC ou pelo Conselho Estadual de Educação-CEE, assim como os títulos de pós-graduação stricto sensu reconhecidos pela CAPES. O Título de Especialista é auferido por Sociedades, Associações e Colégios de Especialistas de Enfermagem.

A SOBEP realiza concurso para titulação de especialista em Enfermagem Pediátrica ou Neonatológica uma vez a cada dois anos durante a realização do Congresso Brasileiro de Enfermagem Pediátrica e Neonatal. Podem se inscrever enfermeiros que concluíram os cursos de especialização, residência, mestrado e doutorado e, enfermeiros que comprovem atuação no ensino, pesquisa ou assistência na área da especialidade, por no mínimo três anos.

Em um artigo recente com o objetivo de diagnosticar a oferta de cursos de especialização em enfermagem pediátrica e neonatológica nas Instituições de Ensino Superior brasileiras, os autores identificaram que os cursos de especialização se concentram na região sudeste e são, na sua maioria, ofertados por instituições privadas. Ademais, inexiste uma matriz curricular mínima para direcionar os projetos pedagógicos destes cursos. Os Programas de Residência em Enfer- 
magem se constituem em estratégia efetiva de formação especializada, contudo, ainda são incipientes no Brasil, com baixa oferta de vagas. ${ }^{(2)}$

Diante da escassez de cursos de especialização bem como, diante da não padronização de um currículo mínimo de formação e, partindo-se do pressuposto de que a SOBEP lidera a discussão acerca da formação do especialista, apontando as competências e habilidades necessárias para este profissional. Denota-se a importância da reflexão sobre o processo de obtenção do título de especialista a partir dos concursos promovidos por esta Sociedade, já que ainda não se configura como um procedimento padrão ou obrigatório para a Enfermagem.

O enfermeiro que participa do concurso para obtenção do título de especialista é submetido a uma avaliação objetiva da sua qualificação profissional por meio de análise curricular e avaliação teórica. Aqueles que são aprovados nessas etapas de avaliação passam a ser reconhecidos pela SOBEP como enfermeiros que possuem as competências necessárias à prática dessas especialidades no Brasil. Nesta direção, destaca-se também a importância dos egressos dos cursos de especialização e de programas de residência submeter-se a esta avaliação para certificação da qualificação de especialistas, aos moldes do que acontece com a Medicina, que após finalização do curso de residência e/ou especialização os médicos são obrigatoriamente submetidos a uma prova de títulos.

Na enfermagem ainda não está consolidada a obtenção de título de especialista por sociedade de especialistas. Na SOBEP representam um número pequeno diante das incontáveis instituições de saúde que prestam atendimento a esta clientela em todo o território nacional. Uma das razões pode ser a falta de políticas institucionais de incentivo a progressão na carreira aos profissionais especialistas. ${ }^{(3)}$

A SOBEP valoriza o papel do profissional especialista e recomenda que todos os enfermeiros que atuam com neonatos, crianças e adolescentes possuam o título de especialista outorgado por esta Sociedade, a fim de fortalecer e qualificar o cuidado integral e integrado à criança e sua família.

Profa Dra Aline Cristiane Cavicchioli Okido Universidade Federal de São Carlos, São Carlos, SP, Brasil (1) https://orcid.org/0000-0003-4309-5612

DOI: http://dx.doi.org/10.31508/1676-3793202000001

Como citar:

Okido AC. A visibilidade da especialidade e o título de especialista. Rev Soc Bras Enferm Ped. 2020;20(1):4-5.

\section{Referências}

1. Brasil. Conselho Federal de Enfermagem. Resolução COFEN n 581, de 11 de julho de 2018: atualiza, no âmbito do Sistema Cofen/ Conselhos Regionais de Enfermagem, os procedimentos para registro de títulos de pós-graduação lato e stricto sensu concedido a enfermeiros e aprova a lista das especialidades. Brasília (DF): Conselho Federal de Enfermagem; 2018.

2. Conterno JR, Toso BR, Rodrigues EC, Mandetta MA. Diagnóstico da formação especializada em enfermagem pediátrica e neonatal no Brasil. Rev Soc Bras Enferm Ped. 2019;19(2):97-110.

3. Silva RM, Luz MD, Fernandes JD, Silva LS, Cordeiro AL, Mota LS. Tornar-se especialista: expectativas dos enfermeiros portugueses após a realização do curso de especialização. Rev Enf Ref. 2018;16(4):147-54. 